\title{
Efecto inhibidor del dióxido de germanio sobre el biofouling del puerto de Mar del Plata
}

\author{
Inhibitory effect of germanium dioxide on \\ biofouling of Mar del Plata harbour
}

\author{
Miriam Pérez $^{1,2}$, Mónica García ${ }^{1}$, Juan Pablo Roldán ${ }^{1}$, \\ Guillermo Blustein ${ }^{1,3}$
}

\footnotetext{
${ }^{1}$ Centro de Investigación y Desarrollo en Tecnología de Pinturas- CIDEPINT, Av. 52 e/ 121 y 122- La Plata, Argentina e-mail: g.blustein@ cidepint.gov.ar

${ }^{2}$ Facultad de Ciencias Naturales y Museo, Universidad Nacional de La Plata; Calle 122 y 60- La Plata, Argentina

${ }^{3}$ Facultad de Ciencias Agrarias y Forestales, Universidad Nacional de La Plata; Calle 60 y 119- La Plata, Argentina e-mail: m.perez@cidepint.gov.ar, m.garcia@cidepint.gov.ar,juan_jpr@hotmail.com
}

\section{RESUMEN}

La fijación del biofouling sobre cualquier tipo de materiales sumergidos acarrea graves pérdidas económicas como consecuencia del deterioro y la salida de servicio de las distintas estructuras. Este asentamiento de organismos que afecta principalmente a embarcaciones, muelles, boyas, granjas de cultivo y tuberías ocurre de forma secuencial, rápida e inmediata después de la inmersión. En principio se asientan organismos microscópicos ("microfouling") sobre un film preformado de macromoléculas orgánicas adsorbidas sobre la superficie sumergida; la exudación de polímeros extracelulares de las bacterias forma una especie de malla que sirve de anclaje, sostén y nutrición para las esporas algales y larvas de organismos macroscópicos que arriban más tarde. Esta comunidad denominada biofouling alcanza un espesor considerable en poco tiempo y por esta razón, se busca para su control formulaciones antifouling eficaces cuyos componentes sean ecológicamente aceptables. La inhibición que ejerce el dióxido de germanio sobre el desarrollo de organismos del microfouling (principalmente diatomeas, hongos y bacterias) plantea la posibilidad de su utilización como compuesto antiincrustante. En este sentido se estudió el efecto del dióxido de germanio incluido en una pintura antiincrustante expuesta en el puerto de Mar del Plata durante el período de verano. Los resultados obtenidos indican que la formulación con dióxido de germanio inhibió no solo el asentamiento de diatomeas sino que también afectó la fijación de especies conspicuas del macrofouling (ascidias solitarias y coloniales, gusanos tubícolas y cirripedios). Sobre la base de estos estudios se puede concluir que el dióxido de germanio puede ser empleado como compuesto antifouling dado que demostró alta efectividad sobre un amplio espectro de organismos integrantes de la comunidad.

Palabras clave: dióxido de germanio, biofouling, pinturas antifouling amigables con el ambiente.

\begin{abstract}
Marine biofouling on any new material immersed in seawater can lead to extra costs due to increased maintenance, or/and even mechanical wear, and/or biodeterioration that require costly antifouling measures. Fouling organisms growing on immersed manmade surfaces affect hulls, piers, buoys, aquaculture and pipes mainly. Following adsorption of a conditioning film of macromolecules, microorganisms which are the primary colonizers ('microfouling'), are found on unprotected surfaces after only a few minutes of immersion. Extracellular polymeric material exudates from bacteria forms a net that permits anchorage and protection for spores of macroalgae and macroinvertebrate larvae which arrive later. This community is called 'biofouling' and develops a thick layer rapidly. As a consequence, the search is orientated to new efficient compounds to formulate environmental friendly antifouling paints.

It is well known the inhibitory effect of germanium dioxide on microfouling organisms (diatoms, fungi and bacteria, mainly) and this property promotes its use as antifouling compound. In this sense, germanium dioxide was incorporated in a soluble matrix paint and its antifouling performance evaluated after exposition in
\end{abstract}


Mar del Plata harbor during summer season.

The results showed that germanium dioxide antifouling coating inhibited not only diatom settlement but also the attachment of most conspicuous species of macrofouling (solitary and colonial ascidians, tubeworms and barnacles). These results may provide a more environmentally friendly alternative for the control of biofouling.

Keywords: germanium dioxide, biofouling, environmental friendly antifouling paints.

\section{INTRODUCCIÓN}

El biofouling es la comunidad de organismos micro y macroscópicos que se asientan sobre estructuras sumergidas en el mar. Dado que en las zonas costeras son muy pocos los sustratos duros naturales disponibles, los organismos bentónicos sésiles encuentran en puertos, boyas, embarcaciones, tuberías, etc. sitios protegidos en donde asegurarse su crecimiento y desarrollo. Esta acumulación de organismos trae aparejadas consecuencias económicas severas en distintas industrias dado que afecta los materiales sobre los cuales se desarrollan (aceros, hormigones, maderas, plásticos), obliga al cese de actividades y eventualmente la salida de servicio para la reparación y/o limpieza de las partes dañadas.

Desde un punto de vista ecológico el biofouling constituye una comunidad y progresa según las fases de una sucesión ecológica. Una vez sumergido el sustrato en el mar se adsorben inmediatamente macromoléculas orgánicas que se encuentran disueltas en el agua formando en pocos minutos una "película condicionante". Esta película ofrece una superficie adecuada para el arribo de los primeros organismos vivos fundamentalmente bacterias, diatomeas y protozoos que conforman el film primario o microfouling. Los exudados poliméricos extracelulares bacterianos forman una malla o red que favorece la posterior llegada de esporas de algas y larvas de invertebrados (mejillones, cirripedios, ascidias, etc.) [1,2]

En el caso particular de las embarcaciones, un aspecto clave en la protección de los cascos para prevenir las incrustaciones biológicas es la utilización de pinturas antiincrustantes o antifouling. Estas pinturas protegen las superficies liberando lentamente distintos compuestos como cobre o estaño, que generan una interface con alta concentración de biocida, de esta forma se impide la fijación del biofouling.

El mercado ofrece una gran variedad de recubrimientos, muchos de ellos con larga vida útil, pero todos incluyen en su formulación componentes altamente tóxicos que contaminan tanto las aguas como los sedimentos. Las legislaciones internacionales vigentes prohíben el uso de organoestánnicos y restringen el uso de compuestos de cobre [3]. Durante los últimos veinte años se ha puesto especial énfasis en la búsqueda de nuevos compuestos de menor impacto ambiental que eviten la fijación de micro y macroorganismos y, consecuentemente, minimicen las pérdidas económicas derivadas de su asentamiento.

El germanio, un elemento perteneciente al grupo 4A de la tabla periódica (junto con carbono, silicio, estaño y plomo), se encuentra ampliamente en los productos de desecho de carbón y la tecnología de coque [4]. Entre las aplicaciones conocidas del germanio, ya sea en su forma elemental o como sulfuro, se encuentran aquellas referidas a la industria de las telecomunicaciones y al campo de la óptica [5].

El germanio está presente en varias plantas medicinales como así también en otros vegetales como porotos, jugo de tomate, ajo y aloe vera. Diversos estudios demuestran que puede acumularse en microorganismos produciendo inhibición del crecimiento en hongos y bacterias en función de factores como $\mathrm{pH}$, temperatura y concentración de ácido silícico intracelular [6]. La toxicidad general del germanio es baja, excepto para el tetrahidruro de germanio, y existen pocas observaciones sobre la toxicidad del germanio en el hombre.

El germanio no es cancerígeno e incluso parece inhibir el desarrollo del cáncer y, en forma de compuesto orgánico de germanio, el espirogermanio, para destruir las células cancerosas. Los compuestos de germanio no presentan actividad mutagénica y pueden, bajo ciertas condiciones, inhibir la actividad mutagénica de otras sustancias [7]. Los aspectos toxicológicos del dióxido de germanio se han evaluado principalmente en estudios exploratorios en animales para evaluar los efectos adversos reportados en seres humanos, quienes consumieron productos que contenían germanio por sus supuestos efectos protectores para la salud [8]. Si bien los metales son resistentes a la degradación; no se han realizado estudios de biodegradación sobre compuestos de germanio. Tampoco se han realizado evaluaciones de riesgo eco-toxicológicas formales sobre los compuestos de germanio ni se han identificado datos de toxicología acuática para compuestos de germanio [8].

Uno de los usos más frecuentes del dióxido de germanio es como inhibidor del crecimiento de diatomeas en distintos cultivos algales [9]. A su vez, se ha incluido en fibras sintéticas para redes de pesca también como un intento de reducir el asentamiento de diatomeas [10]. Tomando como punto de partida la conocida inhibición del dióxido de germanio en el asentamiento de diatomeas se plantea la hipótesis de interrumpir la secuencia de formación del biofouling en su fase inicial, es decir, focalizar la actividad del compuesto 
sobre el microfouling y, por consiguiente, evitar el desarrollo de la comunidad. Siguiendo esta línea de investigación se incorporó dióxido de germanio a una pintura de matriz soluble y se evaluó su actividad en el mar.

\section{MATERIALES Y MÉTODOS}

\subsection{Elaboración y aplicación de las pinturas}

Se preparó una pintura antifouling conteniendo dióxido de germanio (Tabla 1).

El vehículo de la pintura se preparó en una dispersora de alta velocidad agregando lentamente la resina colofonia a la mezcla de solventes. Luego, las pinturas se prepararon en un molino de bolas de $1 \mathrm{~L}$ de capacidad dispersando los pigmentos y los demás componentes en el vehículo durante 24 horas. Las pinturas fueron aplicadas con pincel hasta un espesor final de película seca de $100 \pm 5 \mu \mathrm{m}$, sobre paneles de acrílico ( $8 \mathrm{~cm} \times 12$ $\mathrm{cm}$ ) previamente arenados y desengrasados con tolueno.

\subsection{Ensayos de campo con las pinturas}

Los paneles pintados y dos controles (uno solamente con pintura base y otro sin pintura) se expusieron en el Club de Motonáutica del puerto de Mar del Plata $\left(38^{\circ} 08^{\prime} \mathrm{S}-57^{\circ} 31^{\prime} \mathrm{W}\right)$ sostenidos desde las marinas y a 50 $\mathrm{cm}$ por debajo de la superficie del agua.

El período de muestreo abarcó a los meses más cálidos (noviembre-febrero) que es cuando se registra el mayor grado de incrustación en cuanto a densidad y diversidad de organismos. Una vez transcurrido este período los paneles se trasladaron al laboratorio y se determinaron los porcentajes de cobertura total y por especie aplicando una grilla de 25 puntos al azar [11].

Las experiencias se realizaron por triplicado. Se aplicaron test estadísticos evaluándose los resultados con ANOVA y test de contraste Tukey.

Tabla 1: Composición de las pinturas expresadas en porcentaje en volumen.

\begin{tabular}{l|c|c}
\hline Componentes & $\begin{array}{c}\text { Blanco } \\
\text { (pintura sin } \mathrm{GeO}_{2} \text { ) }\end{array}$ & $\begin{array}{c}\text { Tratamiento } \\
\text { (pintura con } \mathrm{GeO}_{2} \text { ) }\end{array}$ \\
\hline Dióxido de germanio & ------ & 8,0 \\
\hline Tiza & 27,0 & 19,0 \\
\hline Colofonia & 27,0 & 27,0 \\
\hline Ácido oleico & 6,0 & 6,0 \\
\hline Xileno/aguarrás mineral & 40,0 & 40,0 \\
\hline
\end{tabular}

\section{RESULTADOS Y DISCUSIÓN}

El crecimiento del film primario integrado fundamentalmente por bacterias, protozoos y diatomeas representa la fase inicial del desarrollo de la comunidad del biofouling. El tratamiento con dióxido de germanio apunta a evitar el asentamiento de estos organismos a fin de interrumpir la secuencia de formación de la comunidad.

Los resultados obtenidos indican claramente que las pinturas conteniendo dióxido de germanio afectaron la fijación de especies conspicuas del fouling del puerto de Mar del Plata (Figura 1).

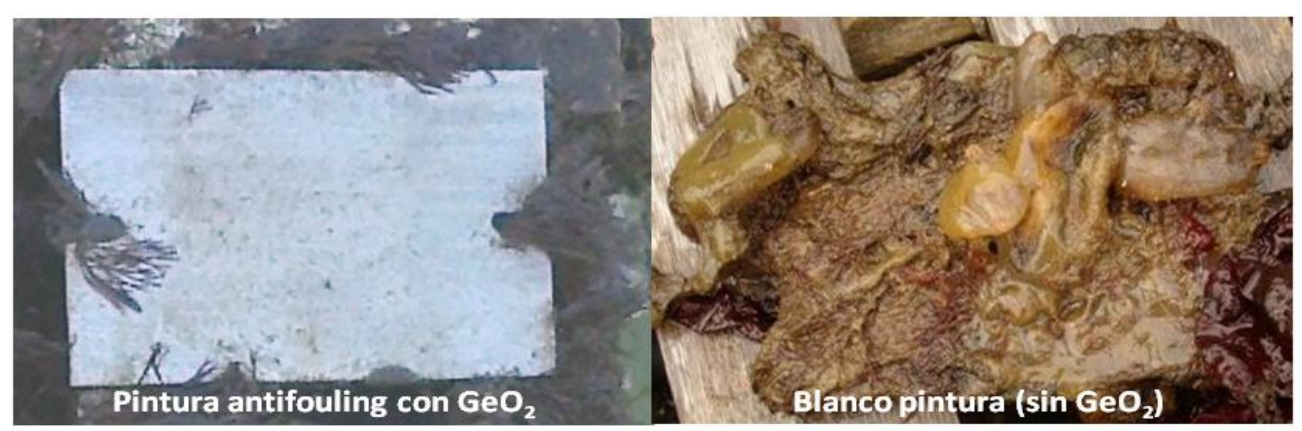

Figura 1: Paneles de acrílico luego de 120 días de inmersión en el puerto de Mar del Plata. 
Los análisis estadísticos revelaron una completa inhibición en el asentamiento de especies calcáreas como Hydroides elegans (Polychaeta, Serpulidae) y el cirripedio cosmopolita Balanus amphitrite (Cirripedia, Balanidae) ambas de gran impacto deteriorante sobre distintos materiales en los que se asientan (acero, fibra de vidrio, madera) [12]. Asimismo, las pinturas ensayadas demostraron un alto poder antiincrustante sobre especies abundantes del fouling "blando" como las ascidias coloniales y solitarias que no solo tienen un efecto negativo porque incrementan el espesor de la incrustación sino también porque generan pHs muy bajos favoreciendo otros fenómenos asociados como la corrosión localizada ("pitting") sobre estructuras de acero $[13,14]$. Por el contrario, el asentamiento de las algas Enteromopha intestinalis y Ectocarpus sp. no fue afectado por la presencia en la interface del dióxido de germanio. En el caso de E. intestinalis no se encontraron diferencias significativas respecto de los controles y se desarrollaron normalmente. Por su parte, Ectocarpus sp. mostró una fijación mayor que en los controles lo que indica que el dióxido de germanio actuó promoviendo su fijación (Figura 2).

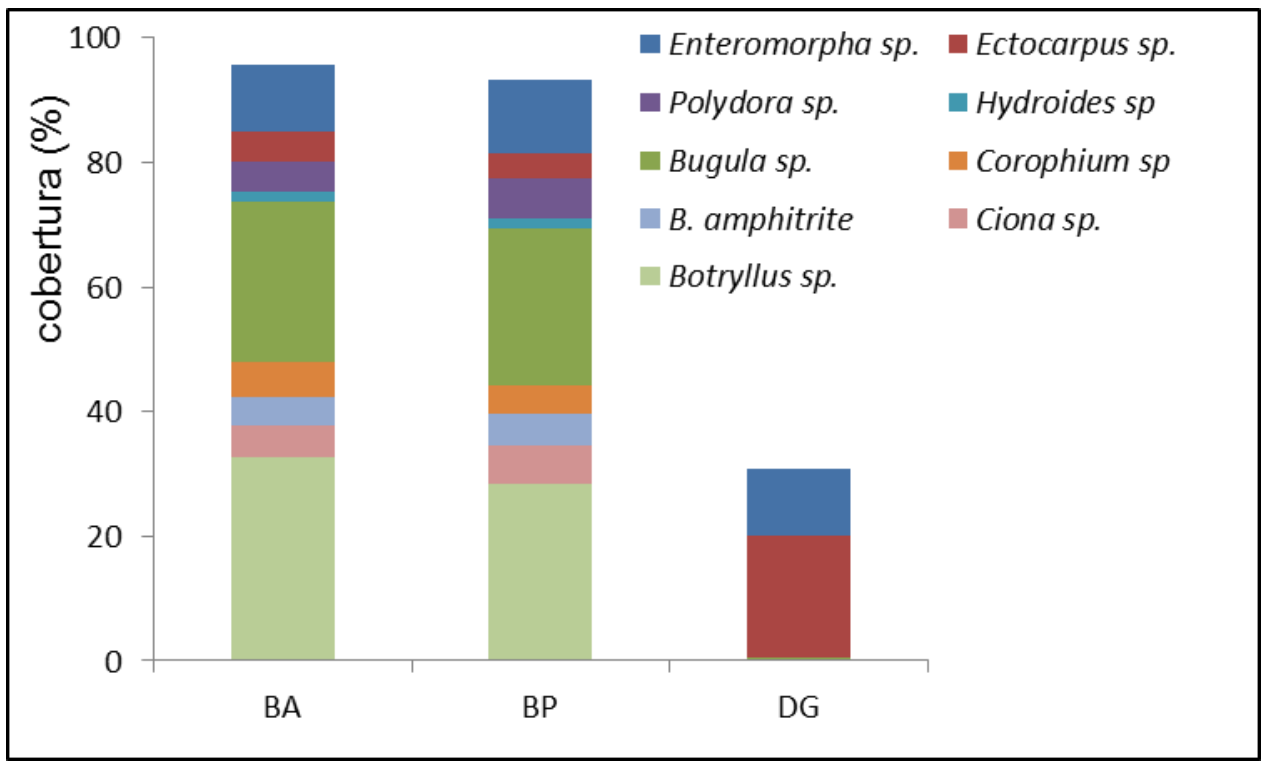

Figura 2: Porcentajes de cobertura de macrofouling.

BA: blanco acrílico; BP: blanco pintura; DG: Pintura con dióxido de germanio.

En estudios previos realizados por otros autores, se demostró también que bajo condiciones de laboratorio el dióxido de germanio no afecta el crecimiento de ciertas macroalgas como Polysiphonia urceolata, Porphyra umbilicalis y Chondrus crispus (Rhodophyta) [15]. Sin embargo, en la gran mayoría de los casos el efecto observado sobre las algas es claramente inhibidor [16-18]. El desarrollo de E. intestinalis y Ectocarpus sp. indica que es necesaria la combinación de más de un pigmento inhibidor para abarcar un espectro más amplio de acción sobre los distintos organismos.

Respecto de la fijación del microfouling la mayoría de las diatomeas fue inhibida completamente por la presencia del dióxido de germanio. Las escasas especies de diatomeas fueron encontradas representando alrededor de un 3\% de la cobertura total evidenciando una marcada reducción en la fijación respecto de los controles (Figura 3).

Los frústulos de diatomeas están formados fundamentalmente por silicio. Por su parte, el germanio tiene propiedades similares a las del silicio y esta similitud sugiere que el ácido germánico $\left(\mathrm{Ge}(\mathrm{OH})_{4}\right)$ podría actuar como un inhibidor competitivo de la utilización del silicio en los organismos que lo requieren como nutriente esencial. Los resultados de trabajos experimentales concluyen que el ácido germánico interfiere en el proceso de silicificación de las diatomeas $[9,19]$. Asimismo, en otros organismos marinos como esponjas silíceas se demostró que la presencia de germanio provoca cambios morfológicos en las espículas durante su deposición intracelular [20,21]. Experimentalmente se comprobó que esta inhibición puede revertirse incrementando la concentración de ácido silícico en el medio, por lo que se infiere una competencia entre $\mathrm{H}_{4} \mathrm{GeO}_{4}$ $\mathrm{y}_{4} \mathrm{SiO}_{4}$. El mecanismo con el que actúa el germanio sobre las diatomeas es fundamentalmente como inhibidor de la división celular más que como responsable de un efecto tóxico lo que apoya su utilización como compuesto "amigable con el medio ambiente" [22]. 
En trabajos realizados sobre la fijación de diatomeas en pinturas comerciales [23] se destaca la importancia del film bacteriano preformado como un condicionante para su desarrollo, lo que impulsa a buscar compuestos que actúen también sobre estos microoorganismos. Otros autores [24] incorporaron dióxido de germanio a una pintura tradicional a base de óxido cuproso con el fin de focalizar la acción antifouling sobre el film primario. La performance antiincrustante obtenida fue muy buena aunque, en este caso, la acción del dióxido de germanio se encuadró en un efecto "booster" es decir, un refuerzo de la acción tóxica del cobre. En los ensayos presentados en este trabajo se apunta hacia una formulación libre de cobre y los resultados apoyan el empleo del dióxido de germanio como pigmento antifouling eficaz. Sin embargo, resulta necesario profundizar en el estudio de otros inhibidores y potenciar el efecto de los compuestos ya conocidos a fin de ampliar el espectro de acción hacia las especies algales que no fueron afectadas.

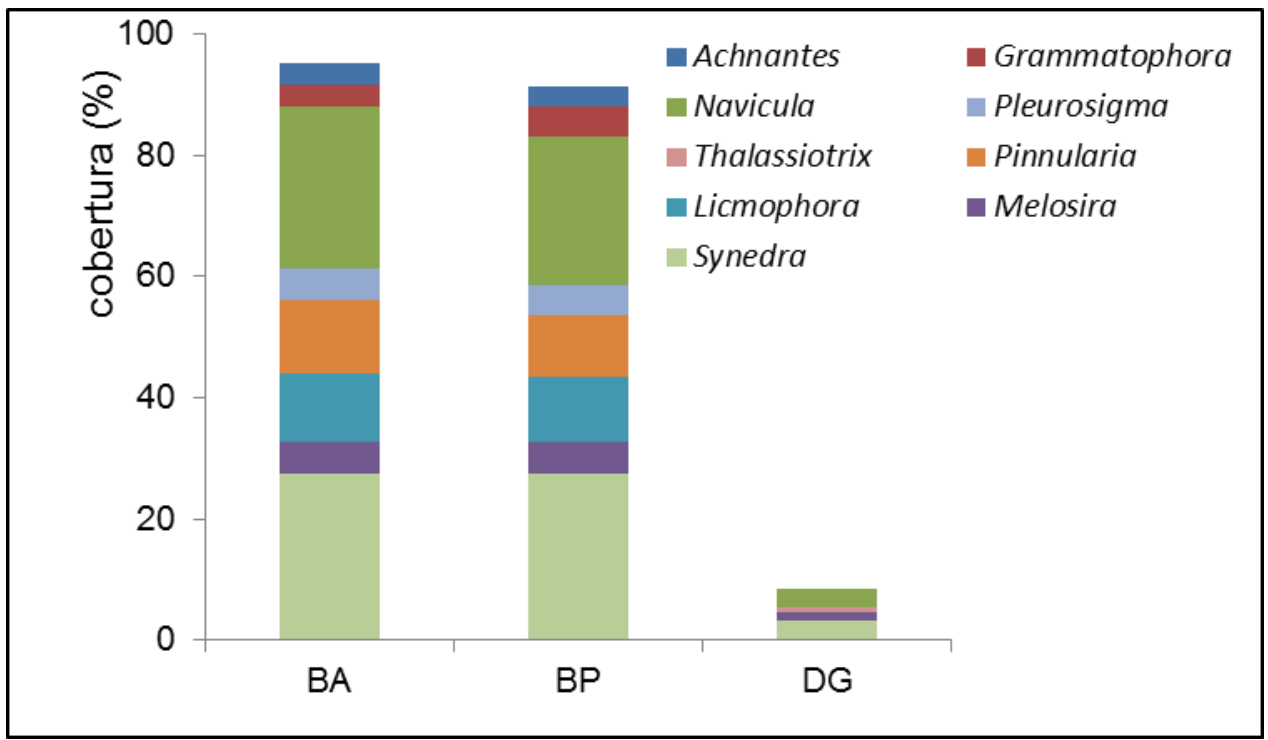

Figura 3: Porcentajes de cobertura de microfouling.

BA: blanco acrílico; BP: blanco pintura; DG: Pintura con dióxido de germanio.

\section{CONCLUSIONES}

Las pinturas antiincrustantes conteniendo dióxido de germanio presentaron una muy buena performance sobre las especies más conspicuas de la comunidad del fouling del puerto de Mar del Plata. Si bien el dióxido de germanio fue muy efectivo sobre la fijación del microfouling, tal como se planteara en la hipótesis de este trabajo, también tuvo un potente efecto inhibidor sobre una gran variedad de organismos del macrofouling. En particular, estas pinturas fueron efectivas sobre especies calcáreas y ascidias que afectan seriamente distintos materiales sumergidos comprometiendo su integridad. Son necesarios más estudios a fin de combinar el dióxido de germanio con otros pigmentos antifouling a fin de lograr una performance antiincrustante de mayor espectro.

\section{AGRADECIMIENTOS}

Los autores agradecen al CONICET, CICPBA y Universidad Nacional de la Plata por el apoyo brindado para realizar este trabajo. Asimismo, desean expresar su agradecimiento a las autoridades del Club de Motonáutica del puerto de Mar del Plata por permitir la utilización de sus marinas para la realización de los muestreos.

\section{BIBLIOGRAFÍA}

[1] WAHL, M., "Marine epibiosis. I. Fouling and antifouling: some basic aspects", Marine Ecology Progress Series, v. 58, pp. 175-189, 1989.

[2] RAILKIN, A., Marine Biofouling: Colonization Processes and Defenses, 1st ed., Boca Raton, Taylor \& Francis, 2004.

[3] BURGESS, J., BOYD, K., ARMSTRONG, E., "The development of a marine natural product-based antifouling paint”, Biofouling, v. 19, pp. 197-205, 2003. 
[4] CHMIELOWSKI, J., KLAPCINSKA, B., "Bioaccumulation of germanium by Pseudomonas putida in the presence of two selected substrates". Applied Environmental Microbiology, v. 51, n. 5, pp. 1099-1103, 1986.

[5] HAYNES, W., CRC Handbook of Chemistry and Physics, 92nd ed., Boca Raton, Taylor \& Francis, 2012.

[6] SLAWSON, R., VAN DYKE, M., LEE, H., et al., "Germanium and silver resistance, accumulation, and toxicity in microorganisms", Plasmid, v. 27, n. 1, pp. 72-79, 1992.

[7] GERBER, G., LÉONARD. A., "Mutagenicity, carcinogenicity and teratogenicity of germanium Compounds", .Mutation Research, v. 387, pp. 141-146, 1997.

[8] BANASIK, M., “Germanium” in Hamilton \& Hardy’s Industrial Toxicology, Raymond, D., Harbison, M., Bourgeois, M., Johnson, G. (eds.), New Jersey, Wiley, 2015.

[9] LEWIN, J., "Silicon metabolism in diatoms. V. Germanium dioxide, a specific inhibitor of diatom growth", Phycologia, v. 6, n. 1, pp. 1-12, 1966.

[10] MINAMI, T., KUSUNOSE, T., "Synthetic fibres for fish nets”, Japanese Kokai Tokyo Koho Patent 78, 21243,1978

[11] FOSTER, M., HARROLD, C., HARDIN, D., "Points versus photo quadrat estimates of the cover of sessile marine organisms", Journal of Experimental Marine Biology and Ecology, v. 146, pp. 193-203, 1991.

[12] MUNN, C., Marine microbiology. Ecology and applications. 2nd ed., New York, Taylor \& Francis, 2011.

[13] HIROSE, E., YAMASHIRO, H., MORI, Y., "Properties of tunic acid in the Ascidian Phallusia nigra (Ascidiidae, Phlebobranchia)", Zoological Science, v. 18, n. 3, pp. 309-314, 2001.

[14] ALDRED, N., CLARE, A., "Mini-review: Impact and dynamics of surface fouling by solitary and compound ascidians", Biofouling, v. 30, n. 3, pp. 259-270, 2014.

[15] MARKHAM, W., HAGMEIER, E., "Observations on the effects of germanium dioxide on the growth of macro-algae and diatoms", Phycologia, v. 21, n. 2, pp. 125-130, 1982.

[16] MCLACHLAN, J., CHEN, L., EDELSTEIN, T., "The culture of four species of Fucus under laboratory conditions", Canadian Journal of Botany, v. 49, pp. 1463-1469, 1971.

[17] TATEWAKI, M., MIZUNO, M., "Growth inhibition by germanium dioxide in various algae, especially in brown algae”, Japanese Journal of Phycology, v. 27, pp. 205-212, 1979.

[18] SHEA, R., CHOPIN, T., "Effects of germanium dioxide, an inhibitor of diatom growth, on the microscopic laboratory cultivation stage of the kelp, Laminaria saccharina". Journal of Applied Phycology, v. 19, n. 1, pp. 27-32, 2007.

[19] AZAM, F., HEMMINGSEN, B., VOLCANI, B., "Germanium incorporation into the silica of diatom cell walls", Archives of Microbiology, v. 92, pp. 11-20, 1973.

[20] ELVIN, D., "Effect of germanium upon development of siliceous spicules of some fresh-water sponges", Experimental Cell Research, v. 72, n. 2, pp. 551-553, 1972.

[21] SIMPSON, T., REFOLO, L., KABY, M., "Effects of germanium on the morphology of silica deposition in a freshwater sponge", Journal of Morphology, v. 159, pp. 343-354, 1979.

[22] BARGHAVA, P., MEDICHERLA, K., "From isolation of potential microalgal strains to strain engineering for biofuel" in The Science of Algal Fuels: Phycology, Geology, Biophotonics, Genomics and Nanotechnology, Gordon, R., Seckbach, J. (eds.), New York, Springer, 2012.

[23] MOLINO, P., CAMPBELL, E., Wetherbee, R., "Development of the initial diatom microfouling layer on antifouling and fouling-release surfaces in temperate and tropical Australia", Biofouling, v. 58, n. 8, pp. 685-693, 2009.

[24] ROBINSON, M., BROWN, L., HALL, B., "Slime films on antifouling paints: control using germanium dioxide", Journal of Coating Technology, v. 58, n. 732, pp. 55-59, 1986. 